\title{
Interactive comment on "Impact of the 2011 off the Pacific coast of Tohoku earthquake on a deep-sea benthic ecosystem: evidence from living and dead benthic foraminifera on the landward slope of the Japan Trench" by Akira Tsujimoto et al.
}

\section{Anonymous Referee \#1}

Received and published: 18 July 2018

I would like to congratulate the authors on their work. This was a very interesting manuscript and its always exciting to see the diversity of tsunami foraminiferal signatures in the sedimentary record explored, particularly from a deep-sea setting.

I think this manuscript needs moderate amendments before publication. My main concerns are largely cosmetic and relate to further detail (substantially more in some areas), clarification and explanation of various elements. I would also advise the use of more cautious language to describe your results as they're based on some relatively low sample sizes in some areas.

Printer-friendly version

Discussion paper 
BGD questions: 1. Does the paper address relevant scientific questions within the scope of BG? Yes 2. Does the paper present novel concepts, ideas, tools, or data? Yes 3. Are substantial conclusions reached? Yes (with additional detail) 4. Are the scientific methods and assumptions valid and clearly outlined? Mostly 5 . Are the results sufficient to support the interpretations and conclusions? Mostly 6. Is the description of experiments and calculations sufficiently complete and precise to allow their reproduction by fellow scientists (traceability of results)? Yes 7. Do the authors give proper credit to related work and clearly indicate their own new/original contribution? Yes 8. Does the title clearly reflect the contents of the paper? Yes but needs cutting back 9 . Does the abstract provide a concise and complete summary? Yes 10. Is the overall presentation well structured and clear? Yes 11. Is the language fluent and precise? Needs work 12. Are mathematical formulae, symbols, abbreviations, and units correctly defined and used? Yes 13. Should any parts of the paper (text, formulae, figures, tables) be clarified, reduced, combined, or eliminated? Some clarification is needed in areas of the text. 14. Are the number and quality of references appropriate? Yes 15. Is the amount and quality of supplementary material appropriate? Further supplementary material would help this paper and future researchers.

Scientific questions: âĂć Pg 3 Lines 11-13: Did you complete any sedimentological analyses or recordings of your cores? Any grainsize or stratigraphic record that you can link your foraminiferal assemblages to? Or sediment coloration (e.g. Munsell colours)? Perhaps an image of the core? This would be particularly useful in highlighting your allochthonous sediments and where you mention the deposition of diatomaceous ooze. âĂć Pg 3 Line 17: What temperature did you oven dry the samples at? This can affect the preservation of agglutinated specimens. âĂć Pg 3 Line 40: Why a $106 \mu \mathrm{m}$ sieve for foraminiferal analyses? That sieve size is an usual gauge and you'd already sieved at $63 \mu \mathrm{m}$ which is standard. Given the depth of your samples (I've found them as small as $30 \mu \mathrm{m}$ from a nearby sample), a $106 \mu \mathrm{m}$ sieve would have caused the loss of many, small heterotrophic species. âÁć Pg 4 Section 3.1: Could you explain the significance of measuring mud and water content stability/lack of stability? âÁć Pg 4

Printer-friendly version

Discussion paper
Interactive comment

\section{2}


Section 3.3: Given the inherent difficulties in foram taxonomy and their potential benefit in being identified to species level in biogeographical studies, it would be good to have a plate of the identified species either as a figure or as a supplementary file/appendix to help future researchers. âĂć Pg 4 Section 3.3: How many species of foraminifera both live and total were identified? âĂć Pg 5 Section 3.3: I would like to see a figure that illustrates the clustering discussed, particularly showing the sub-clustering of the two main assemblages. This can be either as a figure in the main manuscript or as a supplement/appendix. Given the low raw numbers in some sections of core I'm not sure such extensive subdivision is necessary, and I think their subdivision confuses the story you're trying to tell. âÁć Pg 6, section 4.2: You link your foram assemblages to 3 sediment facies that you never explained in your results. What facies? You cannot discuss these without establishing them in the first place. Just saying they exist and marking them on a figure is not enough. âĂć Pg 6, Line 14: Why would diatom blooms accelerate 134Cs deposition? âĂć Pg 6, Lines 19-21: You talk about diatoms and radiolarians in your discussion but they're not mentioned in your methodology or results. How have you quantified them and their significance? Why would diatom blooms accelerate $134 \mathrm{Cs}$ deposition? Why mention the radiolarians? âÁć Pg 7, Line 10: "High species diversity" is relative given your small sample size, actual diversity values would be clearer here. âĂć Pg 8, Section 5: Despite mentioning it in both your abstract and your conclusions nowhere do you report on your allochthonous foraminifera that are deposited between your pre-earthquake and post-earthquake/opportunistic form assemblage. Or did you mean for your downslope transported foraminifera to be your allochthonous assemblage? In any case, it is not clear in your results/discussion.

Technical comments: âÁć The title's wording is very long, contains unnecessary detail for a title and is a bit awkward. I would recommend altering to something like "Impact of the 2011 Tohoku-oki Earthquake on the deep-sea benthos: evidence from foraminifera of the Japan Trench slope". Even "Deep-sea benthic foraminiferal evidence of the 2011 Tohoku-oki Earthquake impact on the Japan Trench" as you only really mention the significance of the downward slope location of your samples in one sentence. âĂć

Printer-friendly version

Discussion paper
Interactive comment 
The English needs correction and tightening up. Many sentences are too long and should be subdivided and the grammar needs a lot of work. âĂć "The 2011 off the Pacific coast of Tohoku earthquake" is a very long-winded name for an even that is well-known and greatly established both in the media and in scientific literature. It should just be referred to as the "2011 Tohoku-oki earthquake". âĂć Figure 10: Why is there a dotted diagonal line above "Reophax Recurvoides, Silicosigmoilina" on the right-side Y-axis? âĂć Pg 7, Line 3 (and elsewhere throughout the manuscript): You cannot start a sentence with an abbreviated species name, it needs to be written in full.

Please also note the supplement to this comment:

https://www.biogeosciences-discuss.net/bg-2018-237/bg-2018-237-RC1-

supplement.pdf

Interactive comment on Biogeosciences Discuss., https://doi.org/10.5194/bg-2018-237, 2018. 